\title{
Self-Reported Assessment of Health Status and Psychological Condition among Hospital Medical Residents in Iran
}

\author{
Soheila Dabiran1, Behrooz Nabaei1, Maede Ghorbany², Farahnaz Khajehnasiri1 ${ }^{*}$ \\ ${ }^{1}$ Department of Community Medicine, School of Medicine, Tehran University of Medical Sciences, Tehran, Iran \\ ${ }^{2}$ School of Medicine, Tehran University of Medical Sciences, Tehran, Iran \\ Email: ${ }^{*}$ khajenasiri@sina.tums.ac.ir
}

Received 12 October 2014; accepted 10 July 2015; published 13 July 2015

Copyright (C) 2015 by authors and Scientific Research Publishing Inc.

This work is licensed under the Creative Commons Attribution International License (CC BY). http://creativecommons.org/licenses/by/4.0/

(c) (i) Open Access

\section{Abstract}

Psychological stress and illness among hospital residences have been subject to increasing scientific scrutiny; however very few studies have been published to describe the extent of health status and psychological stresses in residents in different specialties especially in our country that our study was mainly focused on this subject. Methods: The study subjects were medical residents in public hospitals covering 14 different specialties in Tehran in 2007. A self-administered questionnaire elicited information related to socio-demographic profile, specialty, duty hours, sleep quality, physical activity level, number of night shifts per month, mood changes, sense of depression after night shifts, fatigue, use of antidepressant and tranquilizer, and their opinion regarding their health status on a 4-point Likert scale. Results: $66.7 \%$ of participants were male with the mean age of $32.9 \pm 4.2$ years. $62.1 \%$ of the residents felt mood changes after nightly shifts that could adversely affect their daily living, quality of work, and social relationships. The overall prevalence of the use of antidepressant drugs was $20.0 \%$ which was significantly higher in women than men. Also, $24.4 \%$ of them reported consumption of sedative and hypnotic drugs. $15.6 \%$ reported complete healthy status while $\mathbf{9 . 4 \%}$ reported partial illness. Complete healthy status was more reported among the residents of anesthesiology and pediatrics while illness was more reported by residents in pathology field. Residents' satisfaction with their status was positively correlated with the year of residency and marriage, while dissatisfaction was more reported in divorced ones as well as in those with higher number of nightly shifts. Conclusion: Notable number of hospital residents in Iran experience significant stressors and emotional and mental health problems. Among all studies factors type of specialty, year of residency, female gender, number of nightly shifts, and single marital status were more important than other factors.

\footnotetext{
${ }^{*}$ Corresponding author.
}

How to cite this paper: Dabiran, S., Nabaei, B., Ghorbany, M. and Khajehnasiri, F. (2015) Self-Reported Assessment of Health Status and Psychological Condition among Hospital Medical Residents in Iran. Health, 7, 824-829. 


\section{Keywords}

\section{Health, Status, Psychological, Residents}

\section{Introduction}

Recently, psychological stress and feeling of becoming illness among hospital residences have been subject to increasing scientific scrutiny. Residency is potentially a stressful stage of medical training with working for long hours and high responsibility towards the patients' health and live [1]. Residents not only are expected to be proficient clinicians, educators, researchers and administrators by the time they have completed their training, but also are responsible for managing their especial wards as well as set an acceptable relationship with their patients and other hospital personnel, appropriately [2]. These high workloads and responsibilities have been shown to be associated with worse health status, tendency towards mood imbalance, substance use, and even suicidal thoughts [3]-[5]. Furthermore, this residency-related burnout can result in poor performance, medical errors, and even deterioration of confidence in health services [6]-[8]. Even, sleep deprivation in this group can alone predispose residents to fatigue, more medical and diagnostic errors, antidepressant and sedative drugs, and conflict with healthcare staff [9] [10]. Stress status in residents has been also studied at biological level that the pathological changes in cortisol level have been demonstrated [11]. However, based on our knowledge, very few studies have been published to describe the extent of health status and psychological stresses in hospital residents in different specialties in Iran which was our main purpose in our research.

\section{Materials and Methods}

The population surveyed included medical residents in public hospitals covering 14 different specialties in Tehran in 2007. The Iran medical education system does not allow official residency training in private hospitals and thus all hospitals surveyed in this study were public. The selection was made using disproportionate stratified random sampling with two strata (hospital and resident) those larger hospitals with a larger number of residents is adequately represented. According this sampling method, a minimum sample size of 180 was required for this survey to represent the population of Tehran residents at the $95 \%$ confidence level. Attendance was elective and all participants were informed that responses would be anonymous and were blinded to the scope and purpose ofthe study. We formed all residents in fourteen different medical specialties: anesthesiology $(\mathrm{n}=10)$, cardiology $(n=11)$, emergency medicine $(n=2)$, infectious disease $(n=8)$, internal medicine $(n=22)$, neurology $(n=13)$, neurosurgery $(n=1)$, obstetrics and gynecology $(n=24)$, occupational medicine $(n=1)$, pathology $(n=20)$, pediatrics $(n=35)$, psychiatry $(n=4)$, radiology $(n=19)$, and surgery $(n=12)$.

A self-administered questionnaire was presented to the residents that all of them completed them and returned. This questionnaire consisted of different queries. The first part of questions queried the socio-demographic profile and specialty choices. The second part of the questionnaire was devoted to duty hours, mean hours of sleep per day, sleep quality, physical activity level, and number of night shifts per month. The third part consisted of questions about mood changes and sense of depression after night shifts, appearance of fatigue, and use of antidepressant and tranquilizer. In the last part of the questionnaire, the residents were asked to rate their opinion of different statements regarding their healthy or illness status on a 4-point Likert scale including "completely healthy” (score of 4), "partial healthy” (score of 3), "no illness" (score of 2), and "partial illness” (score of 1).

Results were reported as mean \pm standard deviation (SD) for the quantitative variables and percentages for the categorical variables. The groups were compared using the Student's $t$-test for the continuous variables and the chi-square test (or Fisher's exact test if required) for the categorical variables. P values of 0.05 or less were considered statistically significant. All the statistical analyses were performed using SPSS version 13.0 (SPSS Inc., Chicago, IL, USA) and SAS version 9.1 for Windows (SAS Institute Inc., Cary, NC, USA).

\section{Results}

The response rate for the survey was $100 \%$ and all residents completed the survey (Table 1 ). Among them, $66.7 \%$ $(\mathrm{n}=120)$ were male and $33.3 \%(\mathrm{n}=60)$ were female. The mean age of respondents was $32.9 \pm 4.2$ years that the 
Table 1. Different specialty of studied residents $(n=180)$.

\begin{tabular}{cc}
\hline Specialty & Frequency (\%) \\
Anesthesiology & $10(5.5)$ \\
Cardiology & $11(6.1)$ \\
Emergency medicine & $2(1.1)$ \\
Infectious diseases & $8(4.4)$ \\
Internal medicine & $22(12.2)$ \\
Neurology & $13(7.2)$ \\
Neurosurgery & $1(0.6)$ \\
Obstetrics and gynecology & $24(13.3)$ \\
Occupational medicine & $1(0.6)$ \\
Pathology & $20(11.1)$ \\
Pediatrics & $35(19.4)$ \\
Psychiatry & $4(2.2)$ \\
Radiology & $19(10.6)$ \\
Surgery & $12(6.7)$
\end{tabular}

Data are presented as number (\%).

youngest residents were categorized in the residency fields of neurology, pathology, radiology, and general surgery respectively. Among all the levels of residency, 35.2\% were from first year of post-graduate training and only $5 \%$ were senior. The marital status among residents revealed that $62.1 \%$ of residents surveyed were married, $34.1 \%$ were never married, and $2.7 \%$ were divorced. The mean number of their children was totally 4.0 that 61.0 had no child and $37.9 \%$ had at least one child. No significant difference in mean body mass index between men and women $\left(24.9 \pm 2.7 \mathrm{~kg} / \mathrm{m}^{2}\right.$ vs. $\left.23.0 \pm 3.2 \mathrm{~kg} / \mathrm{m}^{2}\right)$. Respondents' demographic characteristics were similar across the different medical fields surveyed.

The average number of hours worked per day among residents was $9.5 \pm 4.8$ hrs that in women was significantly higher than men and was adversely correlated with the year of residency. The residents of obstetrics and gynecology, surgery, and neurosurgery had the highest hours worked, respectively. The mean hours worked per day was similar between married and non-married ones. Most of the residents usually began their work at 7:30 to $8.00 \mathrm{am}$, but women finished their work earlier than men. With respect to regular physical activity, $56.4 \%$ of the residents had regular weekly physical activities that this rate was highest in the residents of psychiatry and infectious diseases fields, respectively. Also, physical activity was significantly more observed in residents from the last year of post-graduate training and in men more than women.

Regarding quality of sleep, mean nightly shifts per month was 8.5 ranged between 0 and 21 nights. The highest and the lowest number of nightly shifts were reported from the residents of emergency medicine and psychiatry, respectively. $62.1 \%$ of the residents felt mood changes after nightly shifts that could adversely affect their daily living, quality of work, and social relationships. The overall prevalence of the use of antidepressant drugs was $20.0 \%$ that was significantly higher in women than men. Also, 24.4\%of them reported consumption of sedative and hypnotic drugs. $10 \%$ of the participants were current cigarette smoker that $1 \%$ of them were heavy smoker.

Summary of Self-reported illness status is presented in (Table 2). The most frequent reported complains were headache (20.0\%), followed by gastrointestinal problems (18.9\%) and musculoskeletal disorders (17.8\%). Female more than male residents suffered from headache and depression feeling, while dental problems were more reported in men. With respect to the health status, $15.6 \%$ reported complete healthy status, $69.4 \%$ reported partial healthy status, 9.4\% reported partial illness, and only 5.6\% reported no illness. Complete healthy status was 
more reported among the residents of anesthesiology and pediatrics and complete to partial healthy was reported from the residents of pediatrics, internal medicine, and radiology respectively. Besides, residents in pathology field reported illness status more than other fields (Figure 1). Residents' satisfaction with their status was positively correlated with the year of residency and marriage, while dissatisfaction was more reported in divorced one as well as in those with higher number of nightly shifts.

\section{Discussion}

Based on our knowledge, the present study was the first research on health status and psychological stresses among Iranian hospital residents. Totally, we found that the complains of inappropriate health status and psychological problems were significantly associated with female gender, single marital status, and number of nightly shifts that these predicting factors might be potentially resulted in feeling of illness, fatigue, physical problems such as headache, gastrointestinal or musculoskeletal problems, and the use of various antidepressant

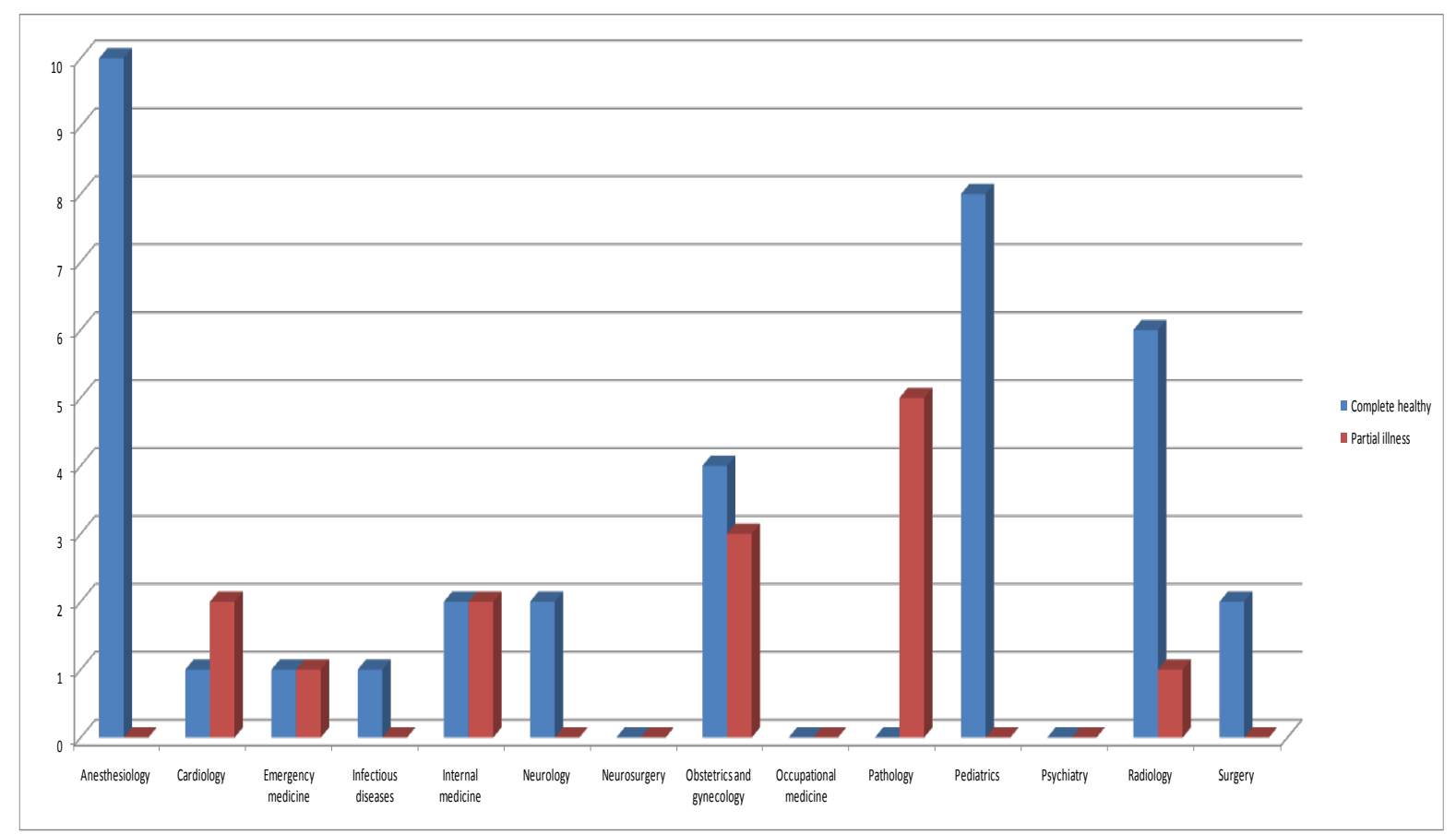

Figure 1. Self-reported complete healthy versus partial illness in different specialties.

Table 2. Self-reported illness status of studied men and women residents $(\mathrm{n}=180)$.

\begin{tabular}{ccccc}
\hline Specialty & $\begin{array}{c}\text { Total } \\
(\mathrm{n}=180)\end{array}$ & $\begin{array}{c}\text { Men } \\
(\mathrm{n}=120)\end{array}$ & $\begin{array}{c}\text { Women } \\
(\mathrm{n}=60)\end{array}$ & P-value \\
\hline Headache & $36(20.0)$ & $15(12.5)$ & $21(35.0)$ & 0.005 \\
Gastrointestinal disorders & $34(18.9)$ & $25(20.8)$ & $9(15.0)$ & 0.432 \\
Musculoskeletal disorders & $32(17.8)$ & $18(15.0)$ & $14(23.3)$ & 0.255 \\
Depression feeling & $28(15.6)$ & $13(10.8)$ & $15(25.0)$ & 0.038 \\
Dental problem & $18(10.0)$ & $17(14.7)$ & $1(1.7)$ & 0.015 \\
Respiratory disorders & $9(5.0)$ & $9(7.5)$ & $0(0.0)$ & 0.059 \\
Psychological disorders & $7(3.9)$ & $5(4.2)$ & $2(3.3)$ & 0.999 \\
Cardiovascular disorders & $4(2.2)$ & $4(3.3)$ & $0(0.0)$ & 0.305 \\
\hline
\end{tabular}

Data are presented as number (\%). 
or sedative drugs. The field of specialty was also a main determinant for feeling illness so that the residents in pathology field reported the highest feeling illness and the residents in anesthesiology and pediatrics reported the highest complete health status. In the review of published literatures, we can clearly reveal similar findings with respect to the main predictors of psychological stresses among medical residents, however the prevalence of these problems are widely varied probably because of the differences in social conditions, worked hours, and even religious approaches. In a study by Waldman et al., high emotional exhaustion and depersonalization was found in the majority of respondents and significant depressive symptoms were found in less than half of residents [12]. In another study by van der Heijden et al. about $12 \%$ of medical residents reported having suicidal thoughts at least 1 time during their residency [13]. In the study by Satterfield and his colleagues, anxiety and guilt were the most commonly reported emotions, followed by positive emotions and anger [14]. Sangi-Haghpeykar et al. reported that the majority of residents (75\% of women and $54 \%$ of men) were identified to be at high levels of stress and this stress situation was positively associated with sexual dysfunction in both genders. This sexual dysfunction could also affect negatively residents' quality of life [15]. Another study suggested that about half of residents reported their life was stressful. Some residents resorted to the use of alcohol (5.2\%), cigarette (1.7\%), drugs and medications (8.6\%) to handle stress. Thirty percent of the residents admitted to have had emotional or mental health problems during the residency program. About $29 \%$ will require further screening for depression, $21.6 \%$ for panic disorder, $15.8 \%$ for generalized anxiety, $9.3 \%$ for social phobia and $8.8 \%$ for agoraphobia [16]. Martini et al. showed that $50 \%$ of residents met burnout criteria, ranging from $75 \%$ (obstetrics/gynecology) to $27 \%$ (family medicine). The first year of residency, being single, personal stress, and dissatisfaction with faculty were independently associated with burnout [17]. Similar to our study, Cohen [2] could show that women reported stress more frequently than males and the time pressure was reported as the number one factor contributing to stress. Also, similar to our finding, Castelo-Branco et al. suggested that the single marital status and workload in office practice were found to be significant predisposing factors as stressors [18].

We also found that the hours of sleep and high nightly shifts could effectively influence residents' health quality and thus were more likely to be involved in their daily living, quality of work, and social relationships. On the other hand, total work hours especially within nightly shifts were significantly correlated with personal accident or injury, a serious conflict with other staff and family members as well as making more medical errors. This sleep loss not only adversely affect personal and social networks abnormalities, but also can affect quality of learning and cognition; job performance, including professionalism and task performance [19].

\section{Conclusion}

It seems that several factors can be stressful and trigger for feeling illness and mental problems among medical residents and among them, type of specialty, female gender, number of nightly shifts, and single marital status were more important than other triggering factors. In fact, understanding of residents' psychological problems can be enhanced by more rigorous research such as studying large samples of residents in carefully planned prospective studies.

\section{Acknowledgements}

The authors thank for the support provided to complete this study.

\section{References}

[1] Msaouel, P., Keramaris, N.C., Tasoulis, A., Kolokythas, D., Syrmos, N., Pararas, N., Thireos, E. and Lionis, C. (2010) Burnout and Training Satisfaction of Medical Residents in Greece: Will the European Work Time Directive Make a Difference? Human Resources for Health, 8, 16. http://dx.doi.org/10.1186/1478-4491-8-16

[2] Cohen, J.S. and Patten, S. (2005) Well-Being in Residency Training: A Survey Examining Resident Physician Satisfaction Both within and Outside of Residency Training and Mental Health in Alberta. BMC Medical Education, 5, 21. http://dx.doi.org/10.1186/1472-6920-5-21

[3] Prins, J.T., Gazendam-Donofrio, S.M., Tubben, B.J., van der Heijden, F.M., van de Wiel, H.B. and Hoekstra-Weebers, J.E. (2007) Burnout in Medical Residents: A Review. Medical Education, 41, 788-800. http://dx.doi.org/10.1111/j.1365-2923.2007.02797.x

[4] van der Heijden, F., Dillingh, G., Bakker, A. and Prins, J. (2008) Suicidal Thoughts among Medical Residents with 
Burnout. Archives of Suicide Research, 12, 344-346. http://dx.doi.org/10.1080/13811110802325349

[5] Hillhouse, J.J., Adler, C.M. and Walters, D.N. (2000) A Simple Model of Stress, Burnout and Symptomatology in Medical Residents: A Longitudinal Study. Psychology, Health \& Medicine, 5, 63-73. http://dx.doi.org/10.1080/135485000106016

[6] Prins, J.T., van der Heijden, F.M., Hoekstra-Weebers, J.E., Bakker, A.B., van de Wiel, H.B. and Jacobs, B., Gazendam-Donofrio, S.M. (2009) Burnout, Engagement and Resident Physicians’ Self-Reported Errors. Psychology, Health and Medicin, 6, 654-666. http://dx.doi.org/10.1080/13548500903311554

[7] West, C.P., Tan, A.D., Habermann, T.M., Sloan, J.A. and Shanafelt, T.D. (2009) Association of Resident Fatigue and Distress with Perceived Medical Errors. The Journal of the American Medical Association, 302, 1294-1300. http://dx.doi.org/10.1001/jama.2009.1389

[8] von dem Knesebeck, O., Klein, J., Grosse Frie, K., Blum, K. and Siegrist, J. (2010) Psychosocial Stress among Hospital Doctors in Surgical Fields: Results of a Nationwide Survey in Germany. Deutsches Arzteblatt International, 14, 248-253.

[9] Baldwin, D.C. and Daugherty, S.R. (2004) Sleep Deprivation and Fatigue in Residency Training: Results of a National Survey of First- and Second-Year Residents. Sleep, 3, 371-372.

[10] Williams, L.S. (1997) Manitoba Suicides Force Consideration of Stresses Facing Medical Residents. Canadian Medical Association Journal, 11, 1599-1602.

[11] Coeck, C., Jorens, P.G., Vandevivere, J. and Mahler, C. (1991) ACTH and Cortisol Levels during Residency Training. The New England Journal of Medicine, 325, 738.

[12] Waldman, S.V., Diez, J.C., Arazi, H.C., Linetzky, B., Guinjoan, S. and Grancelli, H. (2009) Burnout, Perceived Stress, and Depression among Cardiology Residents in Argentina. Academic Psychiatry, 33, 296-301.

http://dx.doi.org/10.1176/appi.ap.33.4.296

[13] van der Heijden, F., Dillingh, G., Bakker, A. and Prins, J. (2008) Suicidal Thoughts among Medical Residents with Burnout. Archive of Suicide Research, 12, 344-346. http://dx.doi.org/10.1080/13811110802325349

[14] Satterfield, J.M. and Becerra, C. (2010) Developmental Challenges, Stressors and Coping strategies in Medical Residents: A Qualitative Analysis of Support Groups. Medical Education, 44, 908-916. http://dx.doi.org/10.1111/j.1365-2923.2010.03736.x

[15] Sangi-Haghpeykar, H., Ambani, D.S. and Carson, S.A. (2009) Stress, Workload, Sexual Well-Being and Quality of Life among Physician Residents in Training. International Journal of Clinical Practice, 63, 462-467. http://dx.doi.org/10.1111/j.1742-1241.2008.01845.x

[16] Ogunsemi, O.O., Alebiosu, O.C. and Shorunmu, O.T. (2010) A Survey of Perceived Stress, Intimidation, Harassment and Well-Being of Resident Doctors in a Nigerian Teaching Hospital. Nigerian Journal of Clinical Practice, 13, 183-186.

[17] Martini, S., Arfken, C.L., Churchill, A. and Balon, R. (2004) Burnout Comparison among Residents in Different Medical Specialties. Academic Psychiatry, 28, 240-242. http://dx.doi.org/10.1176/appi.ap.28.3.240

[18] Castelo-Branco, C., Figueras, F., Eixarch, E., Quereda, F., Cancelo, M.J., González, S. and Balasch, J. (2007) Stress Symptoms and Burnout in Obstetric and Gynaecology Residents. An International Journal of Obstetrics and Gynaecolog, 114, 94-98. http://dx.doi.org/10.1111/j.1471-0528.2006.01155.x

[19] Papp, K.K., Stoller, E.P., Sage, P., Aikens, J.E., Owens, J., Avidan, A., Phillips, B., Rosen, R. and Strohl, K.P. (2004) The Effects of Sleep Loss and Fatigue on Resident-Physicians: A Multi-Institutional, Mixed-Method Study. Academic Medicine, 79, 394-406. http://dx.doi.org/10.1097/00001888-200405000-00007 